\title{
Effects of catastrophic financial loss on suicide risk: evidence from Korean stock market crash in October 2008
}

\author{
Wonse Kim ${ }^{1,2} \cdot$ Heungju Park ${ }^{3} \cdot$ Jin Joo Park ${ }^{4}$ Woong Kook ${ }^{1}$ (I)
}

Received: 25 November 2020 / Accepted: 18 May 2021 / Published online: 26 May 2021

c) Springer-Verlag GmbH Germany, part of Springer Nature 2021

\begin{abstract}
Purpose The negative effect of catastrophic financial loss on suicide risk is widely perceived but hardly studied in-depth because of various difficulties in designing studies. We empirically investigated the effect utilizing the stock market crash event in October 2008 in South Korea.

Methods We extracted stock market investor data from Korea Exchanges, and mortality data from Microdata Integrated Service of individuals aged 30-60 years. We calculated age-standardized monthly suicide rate per 100,000 persons according to sex and age, and developed intervention analysis with multiplicative seasonal ARIMA model to isolate the effect of the stock market crash on suicide rate.

Results More than $11 \%$ of people aged 30-60 years were directly investing in stocks during stock market crash. In October 2008, both KOSPI and KOSDAQ indexes dropped by $22.67 \%$ and $30.14 \%$, respectively. In November 2008, the suicide rate in males 30-60 years increased by $>40 \%$ compared to the expected levels if there had been no market crash, and in females aged $30-40$ and $40-50$ years, it increased by $101.84 \%$ and $74.81 \%$, respectively. The effect appeared to persist in males, whereas it degenerated with time in females during our sampling period. Suicide was more pronounced in younger age groups and females.

Conclusion In this first in-depth study, the effect of catastrophic financial loss negatively affects suicide risk for an extended period, indicating health and financial authorities should provide a long-term financial and psychological support for people with extreme financial loss.
\end{abstract}

Keywords Catastrophic financial loss $\cdot$ Suicide $\cdot$ Mental health $\cdot$ Mental disorder

Jin Joo Park

jinjooparkmd@gmail.com

$\triangle$ Woong Kook

woongkook@snu.ac.kr

Wonse Kim

aquinasws@snu.ac.kr

1 Department of Mathematical Sciences, Seoul National University, GwanAkRo 1, Gwanak-Gu, Seoul, Republic of Korea

2 MetaEyes, 41, Yonsei-ro 5da-gil, Seodaemun-gu, Seoul, Republic of Korea

3 SKK Business School, Sungkyunkwan University, Jongno-gu, Seoul, Republic of Korea

4 Cardiovascular Center, Division of Cardiology, Department of Internal Medicine, Seoul National University Bundang Hospital, Gumiro 166, Bundang, Seongnam, Gyeonggi-do, Republic of Korea

\section{Introduction}

The harmful effect of catastrophic financial loss on mental health is widely examined in both finance and medicine [1-4], and the adverse effect of poor mental health on suicide risk is also well-examined in psychiatry [5-9]. Nevertheless, the direct effect of catastrophic financial loss on suicide risk has hardly been investigated neither in finance nor in medicine as both suicide and catastrophic financial loss are rare events and studying their relationship in a prospective cohort is generally not feasible.

An increased number of reports on suicide in newspapers after massive losses in the stock market [10-12] suggest that event studies via stock market crashes can be a reasonable approach. However, this approach has the following problems. First, as stock market crashes are usually preceded or accompanied by an economic crisis, it is difficult to isolate the net effect of a stock market crash on suicide risk 
because there may be other competing factors. For example, an increase in unemployment induced by an economic crisis can significantly affect the suicide risk [13-15]. However, while unemployment could lead to financial losses, such losses are not catastrophic in many cases: the loss from the unemployment implies not the realized financial loss, but the loss of expected income sequence. Therefore, there is a time buffer to overcome the loss via various measures, such as reemployment or starting new companies. Moreover, since many countries operate various unemployment support policies, such as unemployment benefit program and unemployment insurance program, many unemployed people receive financial support from the government. Thus, the loss from unemployment is not an appropriate type of financial loss to investigate for our research subject "Effects of catastrophic financial loss on suicide risk" as it is not urgently catastrophic in most individual cases. Second, to make reliable inferences about the effect of a stock market crash on suicide risk from an event study of a stock market crash, the event must result in extreme financial losses for a substantial number of investors.

To overcome these obstacles, we utilized the national death record and stock market investor data in October 2008 in South Korea, as (i) South Korea is one of the few countries where the 2008 financial crisis had minimal impact on the real economy [16] and (ii) the proportion of individual investors' direct investments in the stock market is extremely high compared with those in other countries [17]; as individual investors tend to hold undiversified stock portfolios compared to professional investors, such as fund managers [18], millions of Korean investors might have suffered from extreme financial loss due to their less diversified portfolios during the stock market crash in October 2008.

Therefore, the stock market crash event in October 2008 in South Korea provides us an appropriate opportunity to conduct the event study for investigating the effect of catastrophic financial loss on suicide risk. This is the first indepth analysis about the effect of catastrophic financial loss on suicide risk.

\section{Aims of the study}

This study aimed to estimate the effect of catastrophic financial loss on suicide risk via the event study of Korean stock market crash in October 2008. Specifically, according to the existing finance researches on investors' portfolio preferences, younger and male investors prefer riskier portfolio. Therefore, in this study, we hypothesize that suicide risk of the younger or the males is affected more compared to that of the older or the females as the former would be more likely to experience severe financial loss from the market crash.
Table 1 The estimated number of individual investors and population by sex-age-specific group

\begin{tabular}{|c|c|c|c|}
\hline Age group & $\begin{array}{l}\text { Num. of individual } \\
\text { investors } \\
\text { (A) }\end{array}$ & $\begin{array}{l}\text { Population: } \\
\text { (B) }\end{array}$ & $\begin{array}{l}(\mathrm{A}) /(\mathrm{B}) \\
(\%)\end{array}$ \\
\hline \multicolumn{4}{|l|}{$0-20$ years } \\
\hline Male & 30,921 & $6,256,042$ & 0.49 \\
\hline Female & 20,079 & $5,665,743$ & 0.35 \\
\hline All & 51,000 & $11,921,785$ & 0.43 \\
\hline \multicolumn{4}{|c|}{$20-30$ years } \\
\hline Male & 161,276 & $3,727,944$ & 4.33 \\
\hline Female & 104,724 & $3,497,694$ & 2.99 \\
\hline All & 266,000 & $7,225,638$ & 3.68 \\
\hline \multicolumn{4}{|c|}{$30-40$ years } \\
\hline Male & 571,740 & $4,320,946$ & 13.23 \\
\hline Female & 371,260 & $4,149,348$ & 8.95 \\
\hline All & 943,000 & $8,470,294$ & 11.13 \\
\hline \multicolumn{4}{|c|}{$40-50$ years } \\
\hline Male & 683,299 & $4,410,221$ & 15.49 \\
\hline Female & 443,701 & $4,261,627$ & 10.41 \\
\hline All & $1,127,000$ & $8,671,848$ & 13.00 \\
\hline \multicolumn{4}{|c|}{$50-60$ years } \\
\hline Male & 496,559 & $3,078,799$ & 16.13 \\
\hline Female & 322,441 & $3,061,774$ & 10.53 \\
\hline All & 819,000 & $6,140,573$ & 13.34 \\
\hline \multicolumn{4}{|l|}{$60 \sim$ years } \\
\hline Male & 323,157 & $3,028,945$ & 10.67 \\
\hline Female & 209,843 & $4,081,284$ & 5.14 \\
\hline All & 533,000 & $7,110,229$ & 7.50 \\
\hline
\end{tabular}

\section{Materials and methods}

The study was approved by the institutional review board of the Seoul National University Bundang Hospital.

\section{Korean stock market investor data}

The Korea Exchange provides two major trading boards for the investors: the KOSPI and the KOSDAQ. Stocks listed in the KOSPI are larger in market cap and total assets, whereas smaller stocks are usually listed in the KOSDAQ. We, first, downloaded the monthly stock market index data of the two major trading boards from the Korea Exchange (KRX, http://km.krx.co.kr/) website from January 2001 to December 2017. We, then, estimated the number of individual investors at the end of 2008 from the KRX. There were approximately 2,784,000 male and $1,805,000$ female individual investors in the Korean stock market. We calculated the number of investors in each age and sex group based on the sex ratio of all individual 


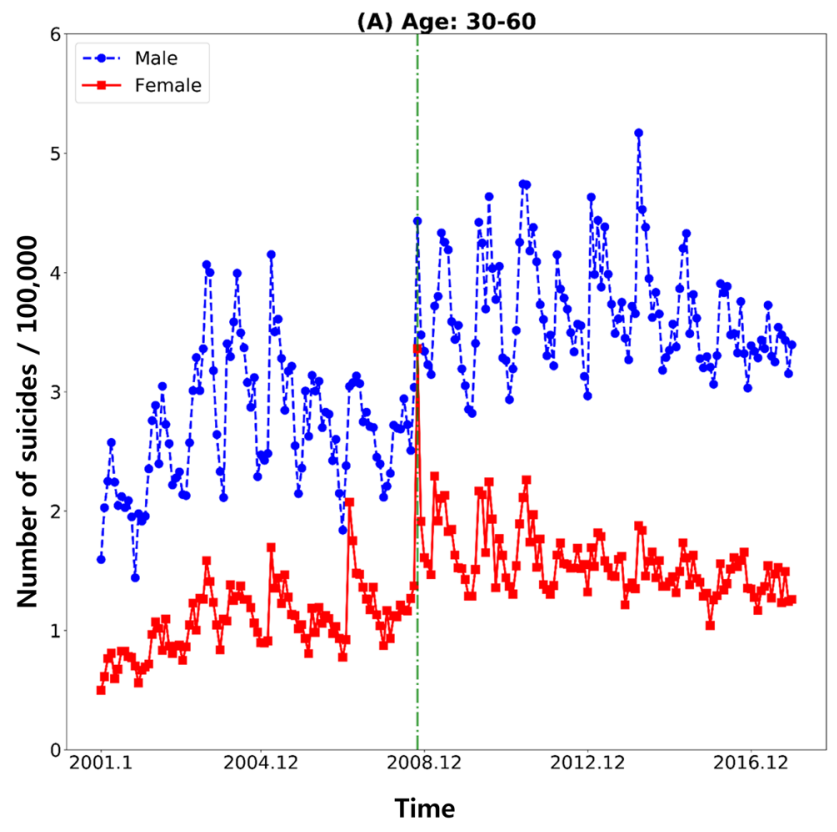

Fig. 1 Monthly suicide rates of time series specific to sex and age from January 2001 to December 2017 (https://mdis.kostat.go. $\mathrm{kr} /$ ). A Monthly suicide rate time series of males and females aged 30-60 years. B Monthly suicide rate time series of males and females

investors which amounted to 1.54:1 (Table 1). More than $11 \%$ of people aged $30-60$ years were investing in stocks during the stock market crash in October 2008, whereas only $0.43 \%$ aged 20 years or less were investing. As there were only few investors aged less than 30 years or older than 60 years, our main target age group was between 30 and 60 years, in which 1 out of 9 persons may have experienced a substantial financial loss during the stock market crash period.

Werther effect, a copycat suicide, is defined as an increase in suicide rate linked to media coverage of suicide, which occurs in persons 'inspired' by reading about or having had a close relationship with a 'successful' suicide. Because the most susceptible persons to Werther effects in Korea are females aged 20-29 years [19], exclusion of persons younger than 30 years would minimize the mixing of Werther and the market crash effect.

\section{Suicide data}

We obtained data on mortality from the Microdata Integrated Service in South Korea (https://mdis.kostat.go.kr/). This data set provides all mortality with cause-of-death from January 1997 to December 2017 in South Korea. For this study, we used the data from January 2001 to December 2017. The cause of deaths is coded using the Korean Classification of Disease-7 (KCD-7), which is a similar system to the International Classification of Diseases-10 (ICD-10).

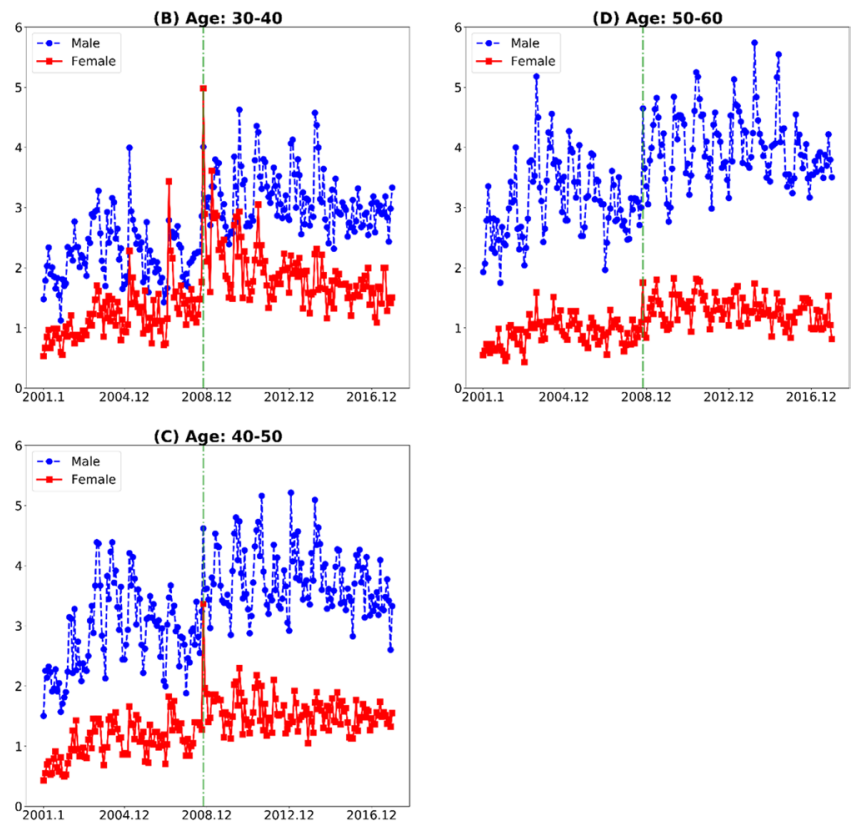

aged 30-40 years. C Monthly suicide rate time series of males and females aged 40-50 years. D Monthly suicide rate time series of males and females aged 50-60 years

We extracted data with the disease code for "intentional self-harm", i.e., suicide (KCD X60-X84). We calculated the age-standardized monthly suicide rate per 100,000 persons according to the gender during this period.

Figure 1 shows the times series of monthly suicide rates according to age and sex. It shows that the dispersion of the times series of each monthly suicide rate was associated with higher levels of the series, i.e. the higher level of the series, the more variation was there around that level, and vice versa. Therefore, we used the log-transformed age-sexspecific monthly suicide rate time series in our study to secure stationarity of the series.

\section{Statistical analyses}

To gage the effect of the Korean stock market crash in October 2008 on suicide risk, we utilized the intervention analysis, which is an established method for analyzing the effect of sudden events in time series data [20,21]. First, we modeled the logged age-sex-specific monthly suicide rate time series, 


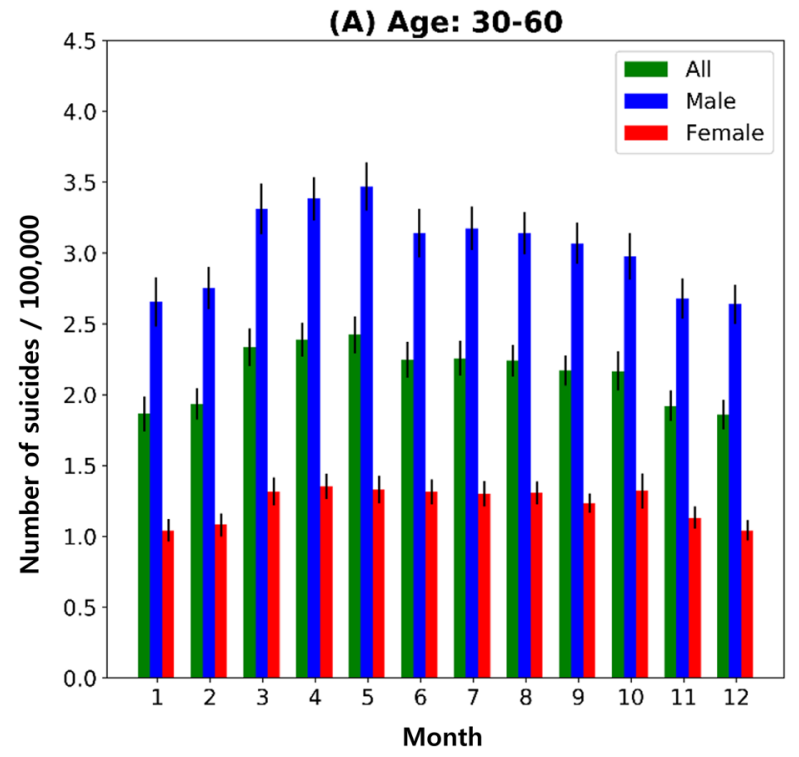

Fig. 2 Average monthly suicide rates specific to sex and age from January 2001 to December 2017. A Average monthly suicide rates of males and females aged 30-60 years. B Average monthly suicide

$\left\{X_{t}\right\}$. To model the time series $\left\{X_{t}\right\}$, we used a multiplicative seasonal ARIMA Model, ARIMA $(p, d, q) \times(R, D, Q)_{12}$ which has been used to model the suicide rate time series in previous studies [22-25]. ${ }^{1}$

In March 2005, February 2007, October 2008, and January 2013, four celebrities committed suicide in South Korea. Therefore, we adjusted for the Werther effect, which is defined as the imitative effect of suicidal behavior following suicides of celebrities [22, 27].

Subsequently, we impounded the intervention effect of the Korean stock market crash in October 2008 (from 1 October 2008 to 31 October 2008) into our $\operatorname{ARIMA}(p, d, q) \times(R, D, Q)_{12}$ models, using a pulse function defined as

$P_{t}^{2008 / 11}=\left\{\begin{array}{l}1, t=\text { November, } 2008 \\ 0, \text { otherwise }\end{array}\right.$

\footnotetext{
1 The parameters of a multiplicative seasonal ARIMA model with seasonal period 12 , which is denoted by \$\$ARIMAlleft(p,d,qlright)। times $\{$ left(R,D,Qlright $)\}_{-}\{12\} \$ \$$, consist of two parts: non-seasonal (regular) orders $p, d$, and $q$, and seasonal orders $P, D$, and $Q$. In the model, the parameters $p$ and $P$ indicate the orders of non-seasonal and seasonal AR characteristic polynomials, respectively, and $q$ and $Q$ represent the orders of non-seasonal and seasonal MA characteristic polynomials, respectively. The parameter $d$, and $D$ denote the orders of non-seasonal and seasonal differences of the model. For more details, refer to $\mathrm{Ch} 10$ of [26] for example.
}
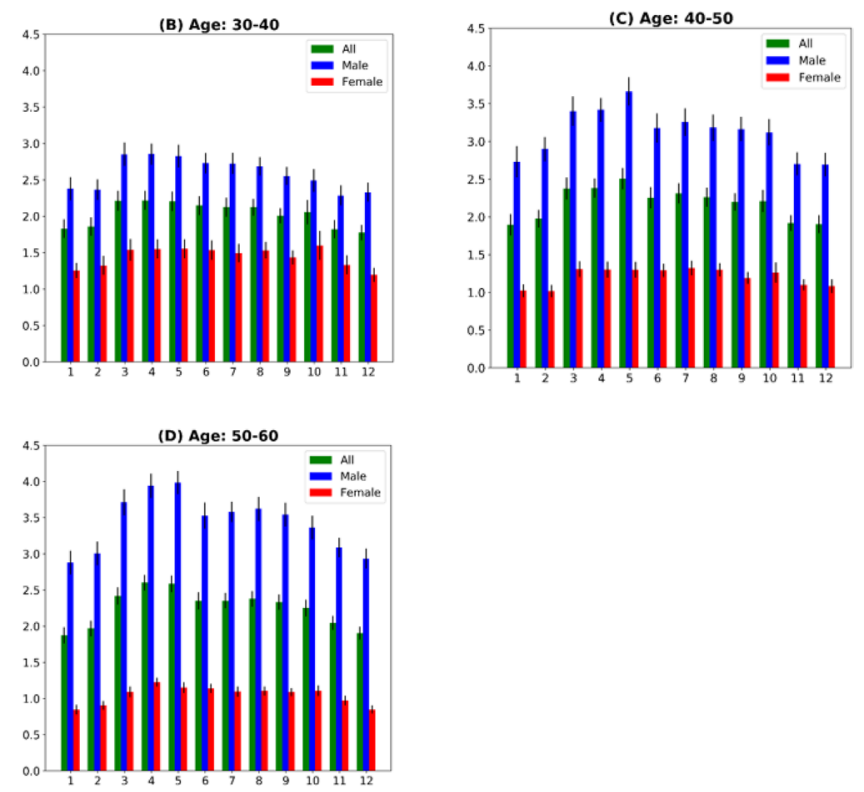

rates of males and females aged 30-40 years. C Average monthly suicide rates of males and females aged $40-50$ years. D Average monthly suicide rates of males and females aged 50-60 years

which reflects the temporary effect of an event, or a step function defined as

$S_{t}^{2008 / 11}=\left\{\begin{array}{l}1, t \geq \text { November, } 2008 \\ 0, \text { otherwise }\end{array}\right.$

which reflects the permanent effect of an event. The final intervention model for each age-sex-specific logged suicide rate time series was specified based on Akaike information criterion (AIC) [28], the auto-correlation function (ACF), and partial auto-correlation function (PACF).

Our final model for the age-sex-specific monthly logged suicide rate time series, $\left\{X_{t}\right\}$, is given by

$X_{t}=N_{t}+m_{t}$

where $N_{t}$ is modeled by $\operatorname{ARIMA}(p, d, q) \times(R, D, S)_{12}$ model; and $m_{t}$ is an intervention model which is a transfer function model with a pulse function input (1) or step function input (2). In the intervention model (3), the process $\left\{N_{t}\right\}$ represents the underlying time series if there were no stock market crash in October 2008. Thus, it models the "natural" age-sex-specific monthly logged suicide rate time series of South Korea. Meanwhile, the process $\left\{m_{t}\right\}$ models the effect of the stock market crash event in October 2008 on an age-sex-specific monthly suicide rate. Therefore, if the market crash event does not affect the suicide rate of an age-sex-specific group, the estimate of the process $\left\{m_{t}\right\}$ in the time series model (3) of the group would be statistically 
Fig. 3 Unemployment rates in the US and South Korea, and stock market indexes in South Korea from January 2001 to December 2017. A Indexes of the two major trading boards in South Korea, KOSPI and KOSDAQ (https://global.krx. co.kr/). B Seasonally adjusted monthly unemployment rates in the US (https://fred.stlouisfed. org/series/UNRATE) and South Korea (http://kosis.kr/)
(A) Korean Stock Market Indexes, KOSPI \& KOSDAQ

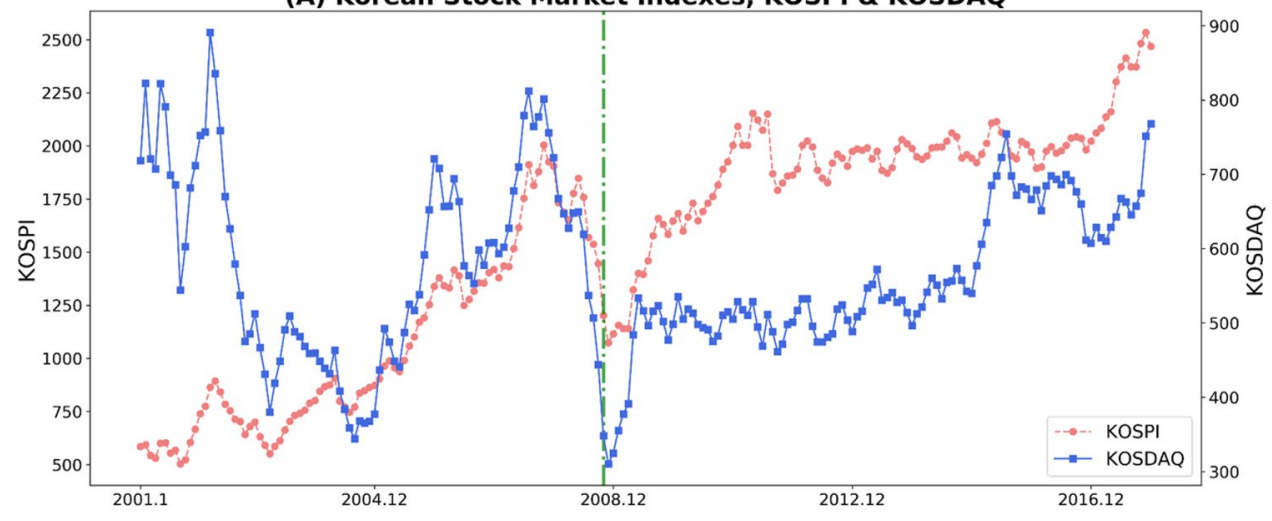

(B) Unemployment rates of U.S and South Korea

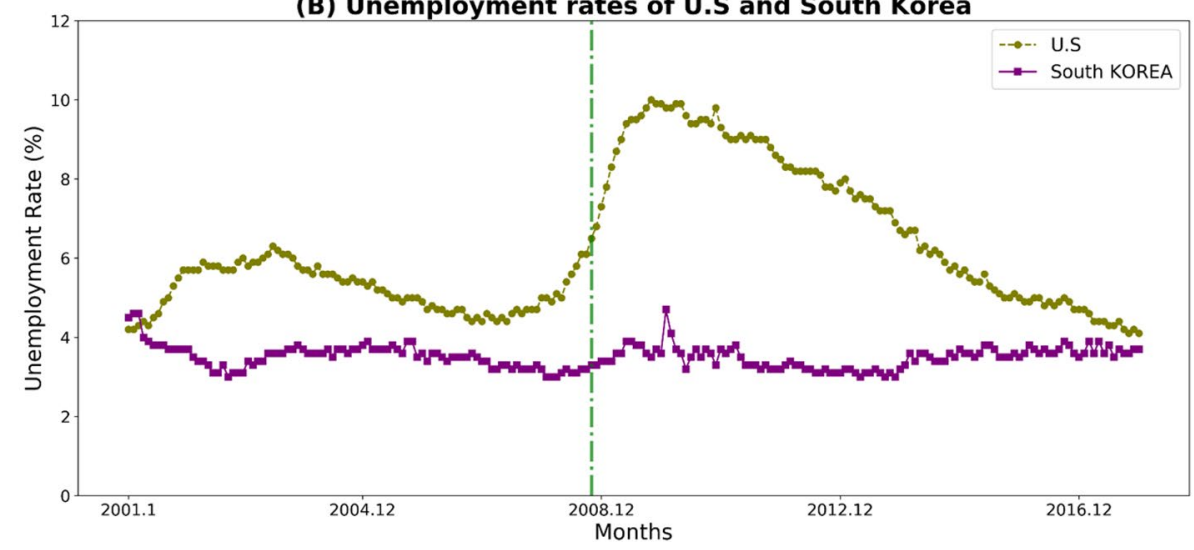

insignificant. For more explanation for intervention models, refer to $\mathrm{Ch} 11$ of [26] for example.

\section{Results}

\section{Statistics of suicide in South Korea, 2001-2017}

Figure 2A displays monthly averages of the suicide rate for the whole study population during the sampling period according to sex with their corresponding standard errors. The suicide rates were greatest in May, and twice higher in males than in females. Similar findings were observed when stratifying patients by age groups (Fig. 2B-D). These results are consistent with previous research on seasonal effects on suicide rates [29-31] and the levels of suicide rate in South Korea [32].

\section{Korean stock market and unemployment rate before and after the stock market crash in October 2008}

Figure 3A shows that in October 2008 (from 1 to 31 October 2008), both KOSPI and KOSDAQ indexes dropped by
$22.67 \%$ and $30.14 \%$, respectively, which was the largest decline during the sampling period. The KOSPI index recovered to its previous level within a year after the stock market crash, whereas the KOSDAQ showed a slower recovery.

Regarding the unemployment rate, South Korea's unemployment rates (seasonally adjusted) remained low before and after the stock market crash. By contrast, there was a rapid increase in the unemployment rate in the United States (Fig. 3B). These results suggest that the impact of the 2008 financial crisis had little impact on the real Korean economy.

\section{The effect of the Korean stock market crash in October 2008 on suicide risk-the empirical results}

The intervention model specification revealed that, whereas no intervention effect of the Korean stock market crash in October 2008 on suicide rate was specified for females aged 50-60 years, the following intervention model was specified for females aged 30-50 years:

$m_{t}:=\frac{\omega}{1-\delta B} P_{t}^{2008 / 11}$ 
Fig. 4 Graphical interpretation of the two intervention model specifications. A The estimated intervention effects of the intervention model $\frac{\omega}{1-\delta B} P_{t}^{2008 / 11}$. B The estimated intervention effects of the intervention model $\alpha \cdot S_{t}^{2008 / 11}$

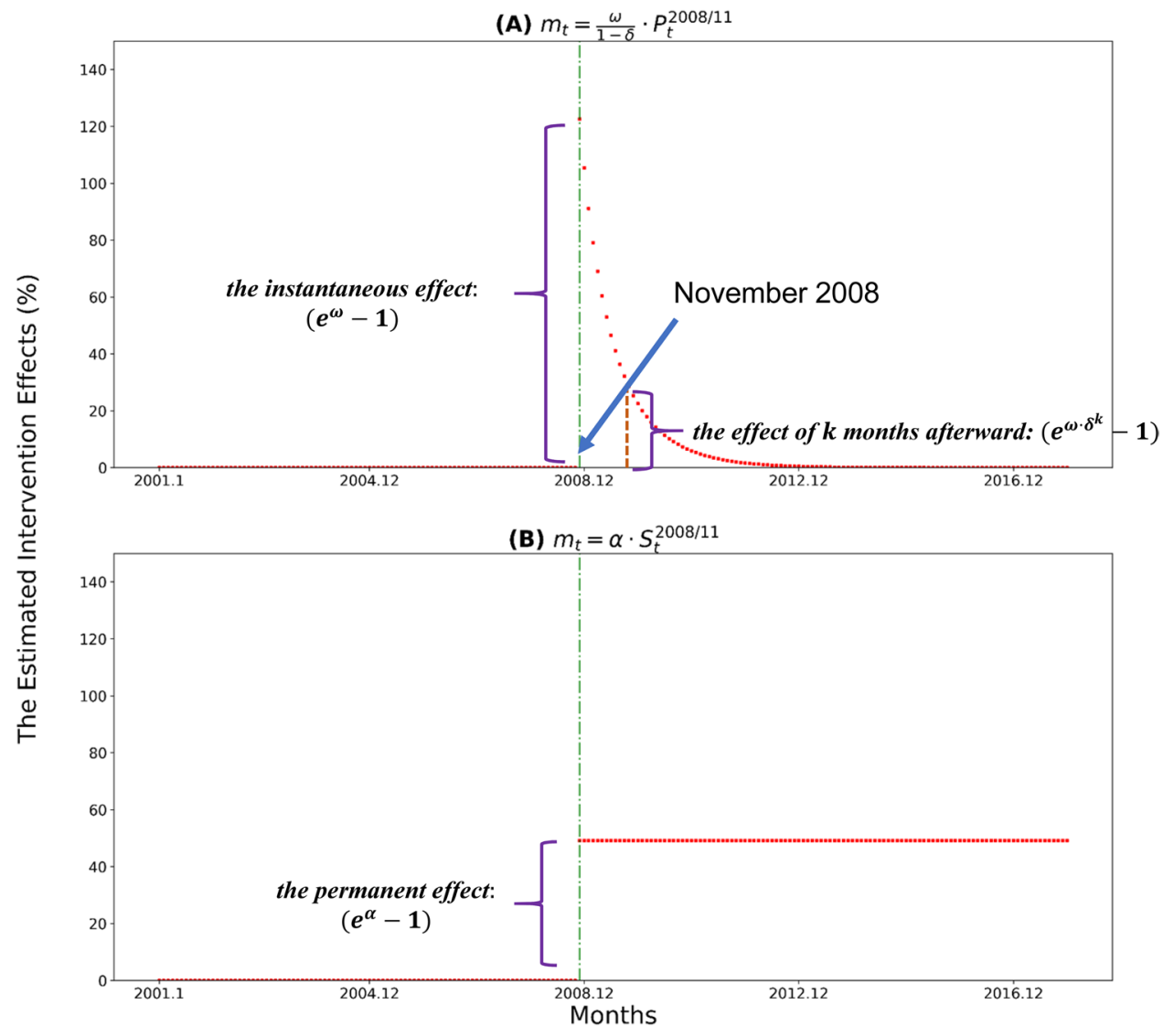

where $B$ denotes the backshift operator such that $B X_{t}=X_{t-1}$. For this intervention model (4), the instantaneous effect of the Korean stock market crash in October 2008 for a monthly suicide rate time series of females aged 30-50 is calculated by $\exp (\omega)-1$, and the effect of the event $k$ months afterward on the series is calculated by $\exp \left(\omega \times \delta^{k}\right)-1$. Figure 4A shows that there was a sudden and unexpected increase in suicide rate in females aged $30-50$ by $\exp (\omega)-1(\%)$ in November 2008, and the magnitude of the effect degenerates exponentially with time. On the other hand, for males, the following intervention model was specified:

$m_{t}:=\alpha \cdot S_{t}^{2008 / 11}$

In this intervention model (4), the permanent effect of the Korean stock market crash in October 2008 for time series of the monthly suicide rate of males aged 30-60 years is gaged by $\exp (\alpha)-1$. There was a sudden and unexpected increase in the suicide rate in males aged 30-60 years by $\exp (\alpha)-1(\%)$ in November 2008, and the magnitude of the intervention effect remained unchanged until the end of the sampling period (Fig. 4B).

Table 2 displays the parameter estimates of the specified intervention models with their corresponding standard errors. The suicide rates of the male groups aged 30 to 60, and female groups aged 30 to 50 increased significantly immediately after the Korean stock market crash. To be more specific, in November 2008, there was an increase in the suicide rate in the male groups aged 30 to 40,40 to 50, and 50 to 60 by $47.22 \%, 40.59 \%$, and $39.26 \%$, respectively, compared to the expected levels if there had been no stock market crash (Table 2). Regarding the females, there was an increase in the suicide rates by $101.84 \%$ and $74.81 \%$ in the 30 to 40 and 40 to 50 age groups, respectively.

Regarding the duration of the impact, Fig. 5 displays the effects of the Korean stock market crash in October 2008 on the suicide $k$ months after the event. The intervention effect of the stock market crash on the suicide rate for males remained constant during our sampling period, whereas that for females degenerated with time and disappeared by the end of our sampling period.

\section{Discussion}

This study investigated the effect of the Korean stock market crash in October 2008 on suicide risk in South Korea using intervention analysis, which is a valid method for analyzing 
Table 2 Intervention model and the estimated impact size of stock market crash on suicide risk

Fig. 5 The estimated intervention effects of the Korean stock market in October 2008 for suicide rates of male and female groups aged 30-60 years in South Korea. A The estimated intervention effects on male groups. B The estimated intervention effects on female groups
Intervention model specifications

\begin{tabular}{|c|c|c|c|c|c|c|c|}
\hline \multicolumn{3}{|c|}{$\alpha \cdot S_{t}^{2008 / 11}$} & \multicolumn{5}{|c|}{$\frac{\omega}{1-\delta B} P_{t}^{2008 / 11}$} \\
\hline $\begin{array}{l}\alpha \\
\text { (SE) }\end{array}$ & $p$-value & $\begin{array}{l}\text { Permanent } \\
\text { effect: } \\
(\exp (\alpha)-1) \\
(\%)\end{array}$ & $\begin{array}{l}\omega \\
(\mathrm{SE})\end{array}$ & $p$-value & $\begin{array}{l}\delta \\
(\mathrm{SE})\end{array}$ & $p$-value & $\begin{array}{l}\text { Instan- } \\
\text { taneous } \\
\text { effect: } \\
(\exp (\omega)-1) \\
(\%)\end{array}$ \\
\hline
\end{tabular}

\begin{tabular}{|c|c|c|c|c|c|c|c|c|}
\hline \multicolumn{9}{|c|}{ Age group 30-40 years } \\
\hline Male & $\begin{array}{l}0.3868 \\
(0.1009)\end{array}$ & $<0.001$ & 47.22 & $\begin{array}{l}- \\
-\end{array}$ & - & - & - & - \\
\hline Female & $\begin{array}{l}- \\
-\end{array}$ & - & - & $\begin{array}{l}0.7023 \\
(0.1144)\end{array}$ & $<0.001$ & $\begin{array}{l}0.9712 \\
(0.0179)\end{array}$ & $<0.001$ & 101.84 \\
\hline \multicolumn{9}{|c|}{ Age group $40-50$ years } \\
\hline Male & $\begin{array}{l}0.3407 \\
(0.0935)\end{array}$ & $<0.001$ & 40.59 & $\begin{array}{l}- \\
-\end{array}$ & - & $\begin{array}{l}- \\
-\end{array}$ & - & - \\
\hline Female & $\begin{array}{l}- \\
-\end{array}$ & - & - & $\begin{array}{l}0.5585 \\
(0.1243)\end{array}$ & $<0.001$ & $\begin{array}{l}0.8254 \\
(0.1027)\end{array}$ & $<0.001$ & 74.81 \\
\hline \multicolumn{9}{|c|}{ Age group 50-60 years } \\
\hline Male & $\begin{array}{l}0.3312 \\
(0.0845)\end{array}$ & $<0.001$ & 39.26 & $\begin{array}{l}- \\
-\end{array}$ & - & - & - & - \\
\hline Female & $\begin{array}{l}- \\
-\end{array}$ & - & - & - & - & - & - & - \\
\hline
\end{tabular}

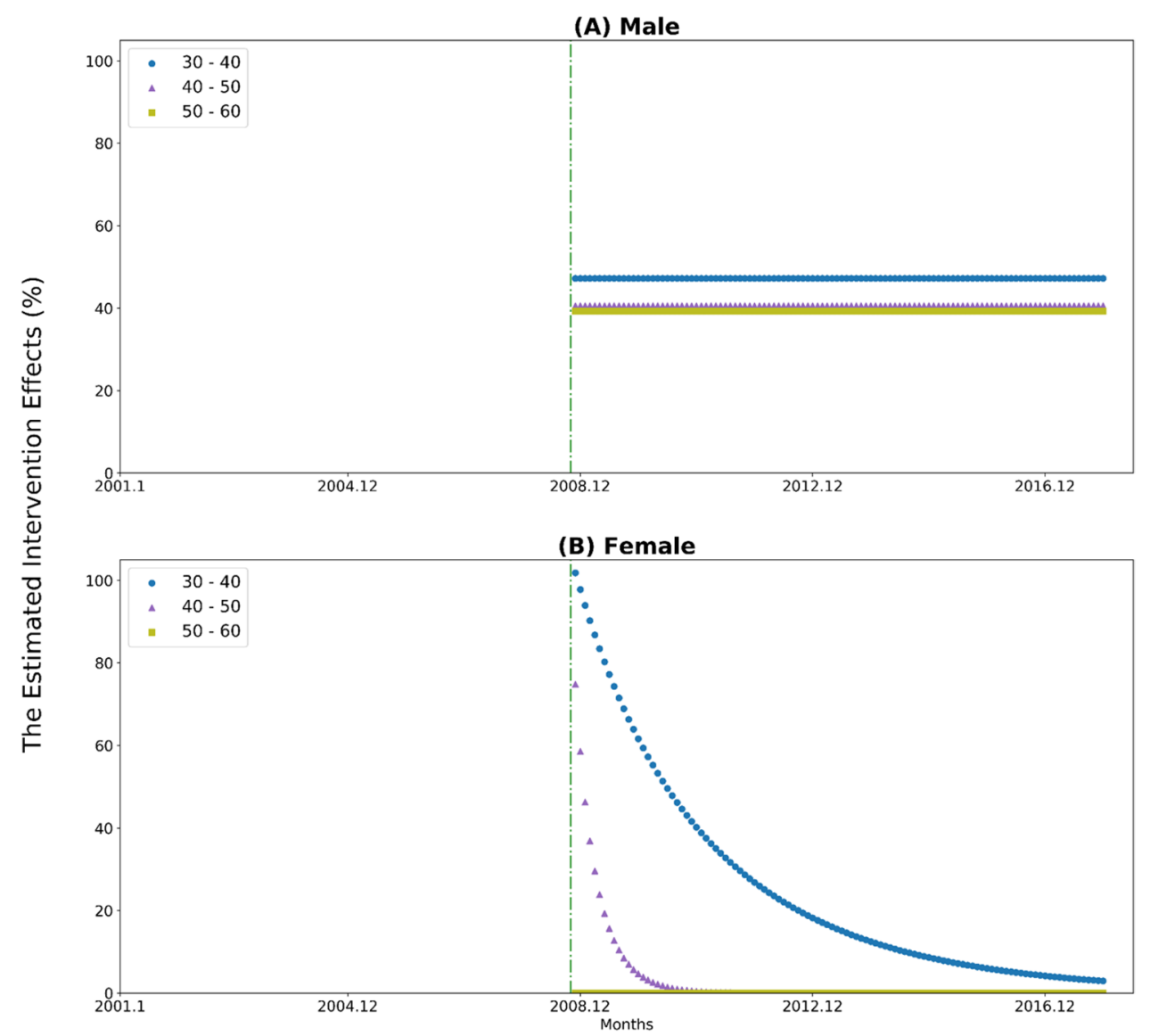


the effect of sudden events on time series data [20,21]. We showed that there was a sudden increase in the suicide rate in the absence of a meaningful increase in the unemployment rate, and the increase in the suicide rate was more dominant in younger age groups. In addition, the impact of the Korean stock market crash on suicide risk differed in terms of duration according to sex: in males, the impact appeared to last permanently during our sample period, whereas in females, it degenerated with time.

Our empirical results showed three key findings. First, there was an unexpected increase in the suicide rate immediately after the stock market crash in the absence of a meaningful increase in the unemployment rate in Korea. This is a unique situation because the global financial crisis in 2008 led to a substantial increase in the unemployment rate in the US and the world. Korea was one of the fastest OECD countries to recover from the economic contraction caused by the 2008 financial crisis [33]. ${ }^{2}$ While Korean stock market was severely affected, its unemployment rate, mainly influenced by the state of real economy, was less affected by the 2008 financial crisis. In summary, under the unique circumstance of Korea and using a state-of-the-art statistical method, we could isolate the impact of the stock market crash on the increase in the suicide rate.

Second, the increase in the suicide rate after the crash was higher in younger age groups which is in line with the finance theory on life-cycle portfolio choice among individual investors [34-39]; the younger an individual investor is, the riskier their portfolio will be Risky portfolios are usually sensitive to the market fluctuations: they yield high profits when market rises but can cause extreme loss when the market crashes. Therefore, younger investors who prefer risky portfolios would have experienced more financial loss during the crash period in October 2008 which might have led to the greater increase in the suicide rates.

Third, the duration of the impact of the stock market crash on suicide differed between males and females. For males, this effect was permanent and lasted until the end of the 9-year sampling period. In females, the deleterious effect had a half-life of 1.5 years and 4 months in the 30-40 and 40-50 years age groups, respectively. These findings are also consistent with previous literature on the gender differences in investing and risk-taking [40-42] which show that women are more conservative and risk averse investors than men and, accordingly, they are less vulnerable to the market crash.

\footnotetext{
${ }^{2}$ For a detailed economic analysis for the primary reasons why Korea was able to quickly escape from the 2008 financial crisis, refer to $\mathrm{Ch} 2$ of [16].
}

\section{Implications}

Since suicide is associated with high social and economic burden, the society should remain alert to emerging risk factors and recognize how known risk factors may be exacerbated [43]. For example, various social supports for unemployment, which is a known suicide risk factor [13-15], are already being provided and developed in many countries. Hence, the suicide risk from unemployment can be managed to some extent at the social level. However, less social support is provided to individual investors who have experienced catastrophic financial loss from a stock market crash because individual investors are supposed to be aware of the risk for the potential loss and to be responsible for their own investment decisions. Consequently, those investors could face much more serious financial state compared to the unemployed. Therefore, the society needs to be alert to a potential suicide risk from stock market crash events.

We confirmed that the stock market crash is associated with an increase in suicide, and this effect was more pronounced in younger investors and lasted longer than previously assumed. The results have important implications for health and financial authorities. Health authorities should provide individual investors who are experiencing extreme financial loss with long-term psychological support including psychiatric treatments to prevent suicide after a stock market crash. They should also provide financial support including financial counseling so that the investors can maintain their normal economic activities and preserve their mental health. Moreover, during the early stage of an ongoing coronavirus pandemic (COVID -19) in 2020, young individual investors were rushing to cash in on the stock market recovery after the global stock market crash through easy-to-use online platform technologies, and some were investing for the very first time [44-46]. At the same time, many famous financial experts, such as Jeremy Grantham, Michael Burry, and Ray Dalio, warned the risk of stock market bubble. Hence, at this time, our empirical results imply that many young individual investors are facing high suicide risk when a stock market crash. Therefore, the financial authorities should additionally provide individual investors, especially young investors, with investment education on portfolio diversifications to minimize the extreme risk of their investment.

Media reporting also has a crucial role. Repetitive reporting of the same suicide may increase suicide rates (i.e. the Werther effect), whereas media reports on mastery of crisis may reduce suicide (i.e. the Papageno effect) [47]. The mode of access to the media also varies with age and gender; therefore, appropriate media should be selected and used. 


\section{Strengths and limitations}

Our study has several limitations. Jin-Sil Choi, one of the most famous actresses in South Korea, committed suicide on 2 October 2008. Ku et al. and Kim et al. reported an increase in suicide after her death concordant with the Werther effect $[22,27]$. Nonetheless, we attempted to control the Werther effect by exclusion of the most vulnerable groups, females aged 20-29 years [19], from our study population and adjustment of the Werther effect in our model. However, there might be residual Werther effect which may have resulted in overestimation of the effect of the Korean stock market crash on the suicide risk. Consequently, because younger females are more vulnerable to the Werther effect $[19,48,49]$, some portion of the large instantaneous effects in females aged $<50$ years may be attributed to the Werther effect. Another major limitation is that we do not have suicide victim specific data. Therefore, it is difficult to separate the specific increase in suicide rate due to financial loss from the total increase right after the stock market crash. In addition, since KRX provides only the total numbers of males and females and the population in each age band, we estimated the numbers of males and females in each age band assuming the sex ratio was equal across the age bands. Therefore, some estimation errors cannot be excluded.

Our study has the following strengths as well. South Korea is one of the few countries where the 2008 financial crisis had minimal impact on the real economy. Hence, we were able to control confounding factors including unemployment rate change due to economic crisis that other countries suffered from during that period. In addition, direct trading by individual investors is very common in Korean stock market and those investors are likely to hold less diversified stock portfolios. Thus, a substantial portion of South Korean investors must have experienced extreme financial loss from the stock market crash in October 2008. Based on these observations, we were able to make statistically sound inferences for the effect of stock market crash event in October 2008 in South Korea on suicide rate. As a result, the study provides an insight into the relationship between catastrophic financial loss and suicide risk.

Author contributions WK, JJP and WK conceived and designed the study concept. WK wrote the draft of the paper and analyzed the data. WK, HP, JJP and WK contributed in writing and reviewing the paper substantively.

Funding W. Kim and W. Kook are partially supported by the National Research Foundation of Korea (NRF) Grant funded by the Korean Government (MSIP) [No. 2018R1A2A3075511]. W. Kook is also partially supported by NRF Grant funded by MSIP [No. 2017R1A5A1015626] and Samsung Electronics [No. IO201211-08045-01]. W. Kim is also partially supported by NRF Grant funded by MSIP [No. 2020R1I1A1A01073151].
Data availability The raw data are not publicly available due to internal policy but are available from the corresponding author on reasonable request.

\section{Declarations}

Conflict of interest The authors declare no competing interests.

\section{References}

1. Ganzini L, McFarland BH, Cutler D (1990) Prevalence of mental disorders after catastrophic financial loss. J Nerv Ment Dis 178(11):680-685

2. Wang Y, Sareen J, Afifi TO, Bolton SL, Johnson EA, Bolton JM (2012) Recent stressful life events and suicide attempt. Psychiatr Ann 42(3): 101-108

3. Engelberg J, Parsons CA (2016) Worrying about the stock market: evidence from hospital admissions. J Financ 71(3):1227-1250

4. Cotti C, Dunn RA, Tefft N (2015) The Dow is killing me: risky health behaviors and the stock market. Health Econ 24(7):803-821

5. Angst J, Angst F, Stassen H (1999) Suicide risk in patients with major depressive disorder. J Clin Psychiatr 60:57

6. Shea SC (1999) The practical art of suicide assessment: a guide for mental health professionals and substance abuse counselors. John Wiley \& Sons Inc

7. Pitman A, Osborn D, King M, Erlangsen A (2014) Effects of suicide bereavement on mental health and suicide risk. The Lancet Psychiatry 1(1):86-94

8. Li H, Luo X, Ke X, Dai Q, Zheng W, Zhang C, Cassidy RM, Soares JC, Zhang X, Ning Y (2017) Major depressive disorder and suicide risk among adult outpatients at several general hospitals in a Chinese Han population. PLoS ONE 12(10):e018614

9. Haney EM, O’Neil ME, Carson S, Low A, Peterson K, Denneson L, Oleksiewicz C, Kansagara D (2012) Suicide risk factors and risk assessment tools: A systematic review. Department of Veterans Affairs (US), Washington (DC)

10. Lowenthal B (1987) The jumpers of '29. Washington Post

11. Lamont J (2008) Sharp rise in Indian investors' suicides. Financial Times

12. Thomas L (2008) Losses mount, fears overwhelm, and a lifeending decision is made. The New York Times

13. Yang B, Lester D (1992) Suicide, homicide and unemployment: a methodological note. Psychol Rep 71(3):844-846

14. Lester D (1994) Suicide and unemployment: a monthly analysis. Psychol Rep 75(1):602-602

15. Lester D, Yang B (2003) Unemployment and suicidal behaviour. J Epidemiol Community Health 57(8):558-559

16. Lin CY-Y, Edvinsson L, Chen J, Beding T (2012) National intellectual capital and the financial crisis in Brazil, Russia, India, China, Korea, and South Africa. Springer Science \& Business Media

17. Chung CY, Wang K (2016) The impact of individual investor trading on information asymmetry in the Korean stock market. The North Am J Econ Financ 37:472-484

18. Barber BM, Odean T (2013) The behavior of individual investors. Handbook of the economics of finance, vol 2. Elsevier, pp 1533-1570

19. Yi H, Hwang J, Bae H-J, Kim N (2019) Age and sex subgroups vulnerable to copycat suicide: evaluation of nationwide data in South Korea. Sci Rep 9(1):1-9 
20. Box GE, Tiao GC (1975) Intervention analysis with applications to economic and environmental problems. J Am Stat Assoc 70(349):70-79

21. Gilmour S, Degenhardt L, Hall W, Day C (2006) Using intervention time series analyses to assess the effects of imperfectly identifiable natural events: a general method and example. BMC Med Res Methodol 6(1):16

22. Fu K-w, Chan C (2013) A study of the impact of thirteen celebrity suicides on subsequent suicide rates in South Korea from 2005 to 2009. PLoS ONE 8(1):e53870

23. Suh S, Chang Y, Kim N (2015) Quantitative exponential modelling of copycat suicides: association with mass media effect in South Korea. Epidemiol Psychiatr Sci 24(2):150-157

24 Bozsonyi K, Osvath P, Fekete S, Bálint L (2016) The effects of significant international sports events on Hungarian suicide rates. Crisis: J Crisis Interv Suicide Prev 37(2):148

25. Park J, Choi N, Kim SJ, Kim S, An H, Lee H-J, Lee YJ (2016) The impact of celebrity suicide on subsequent suicide rates in the general population of Korea from 1990 to 2010. J Korean Med Sci 31(4):598-603

26 Cryer JD, Chan K-S (2008) Time series analysis: with applications in R. Springer Science \& Business Media

27. Kim J-H, Park E-C, Nam J-M, Park S, Cho J, Kim S-J, Choi J-W, Cho E (2013) The Werther effect of two celebrity suicides: an entertainer and a politician. PLoS ONE 8(12):e84876

28. Akaike H (1974) A new look at the statistical model identification. IEEE Trans Autom Control 19(6):716-723

29. Partonen T, Haukka J, Nevanlinna H, Lönnqvist J (2004) Analysis of the seasonal pattern in suicide. J Affect Disord 81(2):133-139

30 Clauss-Ehlers CS (2010) Encyclopedia of cross-cultural school psychology. Springer Science \& Business Media

31. Christodoulou C, Douzenis A, Papadopoulos FC, Papadopoulou A, Bouras G, Gournellis R, Lykouras L (2012) Suicide and seasonality. Acta Psychiatr Scand 125(2):127-146

32. Kwon J-W, Chun H, Cho S-i (2009) A closer look at the increase in suicide rates in South Korea from 1986-2005. BMC Public Health 9(1):72

33. Pascha W (2010) South Korea country report.In: Bertelsmann Stiftung (ed) Managing the crisis. A comparative assessment of economic governance in 14 economies. Bertelsmann Stiftung, Gütersloh

34. Mossin J (1968) Optimal multiperiod portfolio policies. The Journal of Business 41(2):215-229

35 Samuelson PA (1975) Lifetime portfolio selection by dynamic stochastic programming. Stochastic optimization models in finance. Elsevier, pp 517-524

36 Merton RC (1969) Lifetime portfolio selection under uncertainty: The continuous-time case. Rev Econ Stat 51:247-257
37. Merton RC (1975) Optimum consumption and portfolio rules in a continuous-time model. Stochastic optimization models in finance. Elsevier, pp 621-661

38. Benzoni L, Collin-Dufresne P, Goldstein RS (2007) Portfolio choice over the life-cycle when the stock and labor markets are cointegrated. J Financ 62(5):2123-2167

39. Fagereng A, Gottlieb C, Guiso L (2017) Asset market participation and portfolio choice over the life-cycle. J Financ 72(2):705-750

40. Hinz RP, McCarthy DD, Turner JA (1996) Are women conservative investors? Gender differences in participant-directed pension investments. In: Michael S. Gordon, Olivia S. Mitchell, and Marc M. Twinney, eds., Positioning pensions for the twenty-first century. Philadelphia, PA: University of Pennsylvania Press, 1997, pp. $91-103$.

41. Bajtelsmit VL, Bernasek A (1996) Why do women invest differently than men?: Financial counseling and planning. 7(1): 1-10

42. Bajtelsmit V, Bernasek A, Jianakoplos N (1996) Gender effects in pension investment allocation decisions. Center for Pension and Retirement Research:145-156

43 John A, Pirkis J, Gunnell D, Appleby L, Morrissey J (2020) Trends in suicide during the covid-19 pandemic. British Medical Journal Publishing Group

44. Zarroli J (August 11, 2020) Millions Turn To Stock Trading During Pandemic, But Some See Trouble For The Young. NPR: National Public Radio. https://www.npr.org/2020/08/11/89505 4084/millions-turn-to-stock-trading-during-pandemic-but-somesee-trouble-for-the-youn. Accessed March 3, 2021

45. Rega S (October 7, 2020) How Robinhood and Covid opened the floodgates for 13 million amateur stock traders. CNBC: Stock Markets, Business News, Financials, Earnings. https://www.cnbc. com/2020/10/07/how-robinhood-and-covid-introduced-millionsto-the-stock-market.html. March 3, 2021

46. Loudenback T (September 4, 2020) Young investors are flooding into the market for the first time amid a pandemic-and it's not quite as wild as it sounds. Insider Inc. https://www. businessinsider.com/millennials-inves ting-covid-pande mic-new-easy-apps-2020-9.

47. Niederkrotenthaler T, Voracek M, Herberth A, Till B, Strauss M, Etzersdorfer E, Eisenwort B, Sonneck G (2010) Role of media reports in completed and prevented suicide: Werther v. Papageno effects. The British J Psychiatr 197(3):234-243

48. Jang SA, Sung JM, Park JY, Jeon WT (2016) Copycat suicide induced by entertainment celebrity suicides in South Korea. Psychiatry Investig 13(1):74

49. Klostermann P, Ganswindt M, Schneider V (2005) Suicide among adolescents and young adults. Forensic Sci Int 147:S41-S42 